\title{
Mama Tomo dalam Novel Happiness Karya Natsuo Kirino
}

\author{
Yumadia Utami*, Ni Putu Luhur Wedayanti, Ni Luh Putu Ari Sulatri \\ Program Studi Sastra Jepang Fakultas Ilmu Budaya \\ [yumadiautami@gmail.com] \\ Denpasar, Bali, Indonesia \\ *Corresponding Author
}

\begin{abstract}
The title of this research is "Mama Tomo in Happiness, a Novel by Natsuo Kirino". This research aims to analyze the characteristics, group formation, and stratification system of mama tomo group. The methods used are descriptive analysis method and informal method. The theories used in analyzed are sociology literature theory by Wellek and Warren (2016), group characteristics theory by Baron and Kerr (2003), social exchange theory by Blau (in Ritzer and Goodman, 2004), and social stratification theory by Horton and Hunt (1984). Based on the analysis result of the group characteristics, there were three norms found to be applied in the group such as, 1) emphasizing the "wa" or the harmony of group; 2) trying to be an ideal figure of ryousaikenbo; and 3) using the honne and tatemae properly. From the group size, mama tomo group is a small group which has a structure. The structure consists of 1) Ibuki's mom is the leader; 2) Megu's mom is Ibuki's mom's assistant; 3) Mako's mom, Arisa, and Miu's mom are ordinary member. Mama tomo group formation is divided into two factors, that are 1) something in common with another member in group; and 2) obtained benefits of group. The stratification in mama tomo group is determined by three factors, 1) residence; 2) husband's work; and 3) child's school. Two social classes, upper class and middle class also found in mama tomo group. The impacts of the stratification system in mama tomo group are 1) happiness; 2) ethnocentrism of social class; and 3) lifestyle.
\end{abstract}

Keywords: Mama tomo, group, social stratification

\begin{abstract}
Abstrak
Penelitian ini berjudul "Mama Tomo dalam Novel Happiness Karya Natsuo Kirino". Penelitian ini bertujuan untuk mengkaji karakteristik, faktor pembentuk, dan stratifikasi kelompok mama tomo. Metode yang digunakan dalam penelitian ini adalah metode deskriptif analisis dan metode informal. Teori yang digunakan dalam penelitian ini adalah teori sosiologi sastra oleh Wellek dan Warren (2016), teori karakteristik kelompok oleh Baron dan Kerr (2003), teori pertukaran sosial oleh Blau (dalam Ritzer dan Goodman, 2004), dan teori stratifikasi sosial dari Horton dan Hunt (1984). Berdasarkan hasil analisis pada karakteristik kelompok ditemukan tiga norma yang diterapkan pada kelompok mama tomo, yaitu 1) mengutamakan wa atau harmoni kelompok; 2) berusaha mewujudkan sosok ryousaikenbo; dan 3) cerdas dalam menggunakan honne dan tatemae. Dari segi ukuran, kelompok mama tomo memiliki ukuran yang kecil dan memiliki struktur di dalamnya. Struktur tersebut terdiri dari 1) Mama Ibuki sebagai pemimpin; 2) Mama Megu sebagai tangan kanan Mama Ibuki; dan 3) Mama Mako, Arisa dan Mama Miu sebagai anggota biasa. Faktor pembentuk mama tomo terbagi menjadi dua, yaitu 1) adanya kesamaan antar anggota kelompok; dan 2) adanya keuntungan
\end{abstract}

\begin{tabular}{lll}
\hline Info Article & & \\
\hline Received & $:$ & $25^{\text {th }}$ January 2019 \\
Accepted & $:$ & $25^{\text {th }}$ Desember 2019 \\
Publised & $:$ & $29^{\text {th }}$ February 2020
\end{tabular}


yang diperoleh dari kelompok. Stratifikasi dalam mama tomo ditentukan oleh tiga faktor, yaitu 1) tempat tinggal; 2) pekerjaan suami; dan 3) sekolah anak serta ditemukan dua kelas sosial di dalamnya, yaitu kelas atas dan kelas menengah. Adapun dampak dari stratifikasi mama tomo, yaitu 1) kebahagiaan; 2) etnosentrisme kelas sosial; dan 3) gaya hidup.

Kata kunci: Mama tomo, kelompok, stratifikasi sosial

\section{PENDAHULUAN}

Jepang terdiri dari kelompok masyarakat yang hidup bersama dalam sebuah negara. Salah satu kelompok sosial yang muncul di tengah masyarakat Jepang saat ini adalah kelompok mama tomo. Kelompok Mama tomo merupakan kelompok pertemanan ibu yang dikenal melalui anak. Para ibu tersebut membentuk kelompok karena memiliki tujuan yang sama dalam mendorong tumbuh kembang dan pembelajaran anak (Saitou, 2018:15). Akan tetapi, jika ibu tidak pandai menjalin hubungan pertemanan dengan para ibu lain dalam kelompok mama tomo maka anak dikhawatirkan akan mengalami perundungan sehingga mama tomo saat ini menjadi salah satu penyebab dari fenomena perundungan di Jepang (Wada, 2008:197-198).

Munculnya kelompok mama tomo dalam masyarakat Jepang menginspirasi para pengarang Jepang untuk mengangkatnya menjadi sebuah karya sastra, salah satunya adalah novel Happiness karya Natsuo Kirino. Novel ini mengisahkan tentang tokoh Arisa yang merasa tertekan karena sistem stratifikasi yang ada pada kelompok mama tomo yang dibentuknya dengan empat orang ibu, yaitu Mama Ibuki, Mama Megu, Mama Mako, dan Mama Miu. Novel ini dipilih sebagai sumber data dalam penelitian ini karena menyajikan data yang berkaitan dengan karakteristik, faktor pembentuk, dan stratifikasi dalam kelompok mama tomo.

Penelitian ini menggunakan artikel mengenai karakteristik masyarakat Jepang dari Wedayanti (2018) sebagai referensi. Artikel Wedayanti memberikan pemahaman mengenai honne dan tataemae yang digunakan masyakarat Jepang sebagai prinsip hidup mereka. Selain itu, penelitian ini juga menggunakan penelitian mengenai kelompok dalam masyarakat Jepang dari Wea (2016). Penelitian Wea memberikan pemahaman bahwa dalam kelompok terdapat sistem stratifikasi yang berkaitan dengan masalah sosial di Jepang, yaitu perundungan.

Adapun pokok permasalahan yang dibahas pada penelitian ini adalah sebagai berikut.

a) Bagaimanakah karakteristik dan faktor pembentuk mama tomo yang tercermin dalam novel Happiness karya Natsuo Kirino?

b) Bagaimanakah stratifikasi mama tomo yang tercermin dalam novel Happiness karya Natsuo Kirino?

Adapun tujuan dari penelitian ini adalah untuk mengetahui karakteristik, faktor pembentuk, dan stratifikasi mama tomo yang tercermin dalam novel Happiness karya Kirino (2013).

\section{METODE}

Penelitian ini dilakukan dengan metode kepustakaan dan teknik catat dalam pemerolehan data (Ratna, 2014:39), dianalisis dengan metode deskriptif analisis (Ratna, 2014:53), dan disajikan dalam metode informal (Ratna, 2014:50). Adapun teori yang digunakan dalam penelitian ini adalah teori sosiologi sastra oleh Wellek dan Warren (2016) sebagai acuan dasar dalam mengaitkan permasalahan sosial di masyarakat dan permasalahan sosial dalam karya sastra, 
teori karakteristik kelompok oleh Baron dan Kerr (2003) yang digunakan untuk menganalisis karakteristik kelompok mama tomo, teori pertukaran sosial oleh Blau (dalam Ritzer dan Goodman, 2004) yang digunakan untuk menganalisis faktor pembentuk kelompok mama tomo, serta teori stratifikasi sosial dari Horton dan Hunt (1984) yang digunakan untuk menganalisis stratifikasi dalam kelompok mama tomo.

\section{HASIL DAN PEMBAHASAN}

Berikut merupakan penjabaran mengenai hasil analisis pada karakteristik, faktor pembentuk, dan stratifikasi mama tomo yang tercermin dalam novel Happiness karya Natsuo Kirino.

\section{Karakteristik Kelompok Mama Tomo}

Karakteristik kelompok mama tomo dibagi menjadi norma kelompok, ukuran kelompok, dan struktur kelompok. Norma yang berlaku dalam kelompok mama tomo tidak lepas dari norma yang berlaku dalam masyarakat Jepang karena kelompok tersebut terbentuk dalam masyarakat Jepang itu sendiri.

Norma pertama merupakan mengutamakan $w a$ atau harmoni kelompok. Wa merupakan prinsip hidup orang Jepang yang berkaitan dengan shuudan ishiki atau kesadaran berkelompok. Orang Jepang dikenal memiliki kesadaran berkelompok yang tinggi sehingga mereka cenderung berhati-hati dalam berkata dan bertindak demi terjaganya harmoni di antara mereka (Davies dan Ikeno, 2002:109). Dalam novel Happiness prinsip ini dapat dilihat pada tindakan tokoh Arisa yang ditunjukkan pada data berikut.

$$
\begin{aligned}
& \text { さ」 } \\
& \text { 「どこであしょぶの」 } \\
& \text { 「ラウンジだって」 }
\end{aligned}
$$$$
\text { 「いぶママが、遊びましょうって }
$$

「なんだ、らうんじか」

花奈が不満そうに言い捨てた。

BWT の五十二階にあるラウンジ

で遊ぶのは、自分の家とそう変わ

らない気がしてつまらないのだろ

う。しかし、集団遊びでは、自分

の我が儘など通らないことも知つ

ている。玩具は欲しがってる子に

譲りましょう、と論され、お菓子

はお先にどうぞ、と差し上げなさ

いと命ぜられる。

(ハピネス, 2013:17-18)

"Ibu-mama ga, asobimashou tte sa"

"Doko de ashobu no"

"Raunji datte"

"Nanda, raunji ka"

Kana ga fumansou ni iisuteta. BWT no gojuunikai ni aru raunji de asobu no wa, jibun no ie to sou kawaranai ki ga shite tsumaranai no darou. Shikashi, shuudan asobi dewa, jibun no wagamama nado tooranai koto mo shitteiru. Omocha wa hoshigatteru ko ni yuzurimashou, to ron sare, okashi wa osaki ni douzo, to sashiagenasai to meizerareru.

(Happiness, 2013:17-18)

Terjemahan:

"Mama Ibuki mengajak main."

"Main di mana?"

"Katanya di lounge."

"Ah, di lounge." Kana menjawab dengan terpaksa. Ia mungkin merasa bosan karena bermain di lounge yang berada di lantai 52 Bay West Tower sama saja dengan bermain di rumah sendiri. Akan tetapi, Arisa juga mengerti bahwa di dalam kelompok bermain kita tidak boleh 
mementingkan diri sendiri. Kita harus memberikan mainan pada anak yang menginginkannya dan kita diperintahkan untuk mempersilakan orang lain untuk mencicipi kue terlebih dahulu.

Data (1) menunjukkan bahwa Arisa memutusukan untuk mengajak Kana, putrinya untuk bermain bersama anakanak lain yang tergabung dalam kelompok mama tomo Ibuki walaupun Kana sendiri sebenarnya enggan untuk pergi. Keputusan Arisa tersebut didasari oleh pemikiran mengenai wa atau harmoni yang dimiliki orang Jepang. Orang Jepang lebih mementingkan perasaan dan pendapat orang lain karena mereka menganggap hal itu merupakan sikap yang penting untuk diterapkan demi terjaganya harmoni kelompok (Davies dan Ikeno, 2002:110).

Norma kedua yang diterapkan adalah berusaha mewujudkan sosok ryousaikenbo. Ryousaikenbo secara harfiah berarti 'istri yang baik dan ibu yang bijak' dan memiliki kaitan yang erat dengan pandangan masyarakat Jepang akan perempuan. Pandangan ini mulai terbentuk pada Zaman Edo (1603-1868) dan berlanjut hingga saat ini. Salah satu upaya untuk mewujudkan harapan sosial tersebut adalah dengan memperhatikan penampilan. Pada novel Happiness, Arisa dan ibu lainnya digambarkan berusaha menjaga penampilan mereka seperti ditunjukkan pada data berikut.

(2) 仲のいいママたちも、その子供た

ちも、誰もが細くてカッコいい服

装をしている。瘦せなければ服が

似合わないのだから、太つていて

は垢抜けられない。体型維持と所

帯じみないこと。それが、ママた

ちの仲間に入れて貪える条件だし、
カッコいいママと子供たちの集団

であることが、いぶママグループ

の力の源なのだった。

(ハピネス, 2013:16)

Naka no ii mama-tachi mo, sono kodomo-tachi mo, dare mo ga hosokute kakkoii fukusou wo shiteiru. Yasenakereba fuku ga niawanai no dakara, futotteite wa akanukerarenai. Taikei iji to shotaijiminai koto. Sore ga, mama-tachi no nakama ni iretemoraeru jouken dashi, kakkoii mama to kodomo-tachi no shuugou dearu koto ga, Ibu-mama guruирu no chikara no minamoto na no datta.

(Happiness, 2013:16)

Terjemahan:

Baik ibu maupun anak semuanya kurus dan mengenakan pakaian yang bagus. Pakaian tidak akan cocok dan tidak akan terlihat menarik jika gemuk. Oleh karena itu, menjaga berat badan dan tetap awet muda walaupun sudah memiliki anak merupakan syarat agar dapat bergabung dengan para ibu. Selain itu, kekuatan perkumpulan mama tomo dari Mama Ibuki memang ada pada ibu dan anak yang berpenampilan menarik.

Data (2) menunjukkan bahwa penampilan menjadi salah satu syarat agar dapat bergabung dan dapat diterima oleh kelompok mama tomo dari Mama Ibuki. Semua ibu dan anak dalam kelompok tersebut memiliki bentuk tubuh ideal dan selalu mengenakan pakaian yang bagus yang dapat menunjang penampilan mereka. Hal ini berkaitan dengan pandangan masyarakat Jepang akan perempuan yang dinilai harus cantik (Davies dan Ikeno, 2002:141). 
Norma ketiga yang berlaku dalam kelompok mama tomo adalah cerdas dalam menggunakan honne dan tatemae. Honne dan tatemae merupakan salah satu prinsip lain yang menjadi dasar dalam kehidupan orang Jepang. Honne merupakan suara hati seseorang yang biasa digunakan kepada orang yang dinilai dekat. Sebaliknya, tatemae merupakan ungkapan halus yang digunakan seseorang kepada orang lain agar tidak menyakiti perasaan lawan bicara dan agar tercipta $w a$ atau harmoni (Davies dan Ikeno, 2002:93-94). Sebagai bagian dai masyarakat Jepang, Arisa dan ibu lain dalam novel Happiness harus menggunakan prinsip ini secara tepat seperti yang dilakukan Arisa dan Mama Ibuki pada data berikut.

（3）「花奈ちやんママのところ、お盆 にはパパ帰ってらしたの？」

「あ、いや」何と答えようかと迷 つている。「忙しくてね」「ご主 人、IT でしたつけ？」と、真恋 ママが身を乗りだした。「最近の 景気、どうなんですか」

「さあ、あまりよくないんじやな い」

当たり障りのないことを言うと、 美雨ママがメロンを食べながらロ を挟んだ。

「でも、海外勤務でしょう。シ力 ゴだつけ。じや、景気いいじやん」 「優秀でらっしやるのよ」

いぶママが締め括ってくれて、そ の話題は消えそうになった。

"Kana-chan mama no tokoro, obon ni wa papa kaetterashita no?"

"A, iya" nanto kotaeyou ka to mayotteiru. "Isogashikute ne"

"Go-shujin, IT deshitakke?" to, Mako-mama ga mi wo noridashita. "Saikin no keiki, dou nandesuka" "Saa, Amari yokunainjanai" Atarisawari no nai koto wo iu to, Miu-mama ga meron wo tabenagara kuchi wo hasanda.

"Demo, kaigai tsuukin deshou. Shikago dakke. Ja, keiki ii jan"

"Yuushuu de rassharu no yo"

Ibu-mama ga shimekukutte kurete, sono wadai wa kiesou ni natta.

(Happiness, 2013:38)

Terjemahan:

"Mama Kana, apa Papa Kana pulang saat obon kemarin?"

"Ah, tidak." Jawab Arisa bingung. "Dia sibuk."

"Kalau tidak salah suamimu kerja di bidang IT, kan?" Tanya Mama Mako makin penasaran.

"Bagaimana kondisi bisnis akhirakhir ini?"

"Entahlah. Sepertinya kurang baik."

Setelah mengatakan jawaban yang dirasa aman, Mama Miu menyela sambil menikmati melon, "Tapi, suamimu dinas di luar negeri, kan? Kalau tidak salah di Chicago, ya? Kalau begitu kondisi bisnisnya pasti bagus."

"Hebat sekali, ya." Beruntung Mama Ibuki mengakhiri pembicaraan tersebut.

Data (3) menunjukkan bahwa Arisa menjawab dengan hati-hati pertanyaan dari Mama Mako dan Mama Miu yang menanyakan tentang pekerjaan suaminya. Sikap Arisa tersebut dapat dikatakan merupakan upaya cerdas menggunakan tatemae karena topik yang sedang 
dibicarakan merupakan privasi. Selain itu, Mama Ibuki juga cukup cerdas dalam membantu Arisa mengakhiri pembicaraan tersebut dengan memuji suami Arisa.

Selanjutnya jika dilihat dari segi ukuran kelompok, kelompok mama tomo Ibuki merupakan kelompok berukuran kecil karena hanya beranggotakan lima orang anggota, yaitu Mama Ibuki, Mama Megu, Mama Mako, Arisa, dan Mama Miu. Mereka berlima memiliki status dan peran masing-masing dalam kelompok. Mama Ibuki memiliki status sebagai pemimpin kelompok dan berperan sebagai pengkoordinir. Mama Megu memiliki status sebagai tangan kanan Mama Ibuki dan berperan untuk membantunya mengkoordinir kelompok. Sebaliknya, Mama Mako berstatus sebagai anggota biasa yang berperan sebagai penengah. Selain itu, Arisa dan Mama Miu juga berstatus sebagai anggota biasa yang berperan sebagai "warna" dalam kelompok.

Faktor Pembentuk Kelompok Mama Tomo

Kelompok mama tomo terbentuk karena dua faktor, yaitu adanya kesamaan antar anggota mama tomo dan adanya keuntungan yang diperoleh dari kelompok mama tomo.

\section{Adanya Kesamaan Antar Anggota Mama Tomo}

Ada beberapa kesamaan yang dimiliki anggota kelompok mama tomo yang mendasari mereka membentuk kelompok. Kesamaan tersebut berupa pertama, kesamaan daerah tempat tinggal. Kelima ibu dalam novel Happiness digambarkan tinggal di satu daerah yang sama yaitu di Distrik Koto, Tokyo. Kesamaan ini memudahkan mereka untuk bertemu dan melakukan aktivitas bersama. Dengan demikian, baik ibu maupun anak pun dapat lebih mudah mengakrabkan diri masing-masing.
Kedua, kelima ibu tersebut sama-sama memiliki anak perempuan. Kesamaan jenis kelamin anak ini tidak hanya memudahkan ibu untuk saling berbagi pengalaman dan informasi, melainkan juga memudahkan anak karena pola bermain yang sama. Ketiga, kelima ibu tersebut juga memilki pola pikir yang sama bahwa ibu sebaiknya tidak bekerja dan hanya fokus dalam mengurus anak serta rumah tangga. Keempat, kelima ibu tersebut memiliki kesamaan tujuan seperti ditunjukan pada data berikut.

(4) ママ友の仲間は、何があっても皆 で子育ての経験を共有している、 と思い込んでいたのだ。

(ハピネス, 2013:56)

Mama tomo no nakama wa, nani ga attemo minna de kosodate no keiken wo kyouyuu shiteiru, to omoikondeita no da.

(Happiness, 2013:56)

Terjemahan:

Selalu ada dalam benak Arisa bahwa apapun yang terjadi semua harus membagi pengalaman mereka dalam mendidik anak dalam hubungan pertemanan mama tomo.

Data (4) menunjukkan bahwa menurut Arisa tujuan utama dari hubungan mama tomo adalah untuk berbagi pengalaman sebagai seorang ibu. Dengan demikian, mereka dapat menemukan berbagai cara baru dalam merawat, mendidik, dan menghadapi anak karena setiap anak memiliki sifat dan perilaku yang berbeda-beda (Saitou, 2018:51-52).

\section{Adanya Keuntungan yang Diperoleh dari Kelompok Mama Tomo}

Ketertarikan seseorang untuk membentuk kelompok dengan orang lain merupakan pembentukan ikatan awal 
yang akan membawa mereka ke tahap pertukaran untuk mempertahankan dan meningkatkan ikatan antar anggota kelompok. Pertukaran tersebut membuat mereka merasakan sebuah keuntungan baik yang berupa materi maupun berupa berbagai macam hal yang saling dibutuhkan dalam kelompok tersebut (Blau dalam Ritzer dan Goodman, 2004:369-371). Pada novel Happiness, keuntungan pertama yang diperoleh dari kelompok mama tomo adalah pertukaran informasi. Pertukaran informasi ini meliputi informasi mengenai perilaku anak dan kuota kosong di sekolah yang hanya dapat diperoleh jika tergabung dalam kelompok mama tomo. Hal ini dikarenakan menurut Blau (dalam Ritzer dan Goodman, 2004:369) keanggotaan dalam kelompok akan melibatkan pertukaran "hadiah" yang saling menguntungkan satu sama lain.

Keuntungan kedua yang didapat dari kelompok mama tomo adalah aktualisasi diri. Kelompok mama tomo Ibuki dinilai lebih unggul dibandingkan kelompok lain karena rata-rata anggotanya memiliki kemampuan finansial yang tinggi dan berpenampilan baik sehingga membuat mereka merasa bangga memperkenalkan kelompoknya pada orang lain. Contoh lain dari aktualisasi diri ini adalah berupa hal yang bersifat psikologis seperti ditunjukkan pada data berikut.

$$
\begin{aligned}
& \text { 「ほとに、いぶきってどうしよ } \\
& \text { うもないの。花奈ちゃんみたいに } \\
& \text { いい子だったら、どんなにいいか } \\
& \text { と思うわ。花奈ちゃんはきちんと } \\
& \text { ご挨拶できるし、落ち着いている } \\
& \text { し、本当にお利口さんね」 }
\end{aligned}
$$

$$
\text { 「そうかしら。うちの子、おとな }
$$

し過ぎるでしょう。いぶちやんみ
たいに活発だったらいいなと思う わ」

「そんなことないわよ。花奈ちや んもママがいない時は活発だし、 すごく元気よね」

$$
\text { (ハピネス, 2013:126) }
$$

"Honto ni, Ibuki tte doushiyou mo nai no. Kana-chan mitai ni ii ko dattara, donna ni ii ka to omou wa. Kana-chan wa kichinto go-aisatsu dekiru shi, ochitsuiteiru shi, hontou ni orikou-san ne"

"Sou kashira. Uchi no ko, otonashisugiru deshou. Ibu-chan mitai ni kappatsu dattara ii na to omou wa"

"Sonna koto nai wa yo. Kana-chan mo mama ga inai toki wa kappatsu da shi, sugoku genki yo ne"

(Happiness, 2013:126)

Terjemahan:

"Ibuki itu benar-benar tidak bisa apaapa. Coba saja dia bisa seperti Kana. Kana itu bisa menyapa orang dengan sopan, kalem, pintar sekali pokoknya."

"Ah, masa? Anakku terlalu pendiam. Coba saja dia bisa seperti Ibuki yang lincah."

"Ah, tidak juga. Kana juga lincah dan bersemangat kok kalau sedang tidak ada ibunya."

Data (5) menunjukkan bahwa Mama Ibuki dan Arisa sedang memuji putri mereka masing-masing. Pujian seperti ini hanya dapat diperoleh jika tergabung dalam kelompok mama tomo karena semua anggota dalam kelompok tersebut sering melakukan aktivitas bersama sehingga athu akan sifat dan perkembangan satu sama lain baik ibu maupun anak. Pertukaran hadiah yang bersifat psikologis ini dilakukan untuk 
meningkatkan rasa percaya diri sebagai ibu rumah tangga karena menurut Shirakawa (2013:55-56) pekerjaan sebagai ibu rumah tangga merupakan pekerjaan yang sulit mendapatkan apresiasi sehingga hal itu membuat ibu bersaing untuk mendapatkan apresiasi di luar rumah, salah satunya melalui kelompok mama tomo.

\section{Stratifikasi Kelompok Mama Tomo}

Struktur stratifikasi pada kelompok mama tomo dalam novel Happiness dibagi menjadi dua kelas, yaitu kelas atas dan kelas menengah. Namun, karena menurut Horton dan Hunt (1984:6) kelas bawah hanya ditempati oleh para pekerja tidak tetap dan pengangguran maka tidak satu pun anggota dari kelompok mama tomo Ibuki yang termasuk di dalamnya. Berikut merupakan penjabaran dari struktur stratifikasi sosial pada kelompok mama tomo Ibuki.

\section{Kelas Atas}

Pada novel Happiness terdapat tiga ibu yang menempati kelas atas, yaitu Mama Ibuki, Mama Megu, dan Mama Mako. Kelas sosial mereka ditentukan oleh faktor tempat tinggal yang mana mereka menempati posisi tertinggi karena tinggal di Bay West Tower, tower mansion yang paling mahal jika dibandingkan dengan tempat tinggal Arisa atau Mama Miu.

Selain itu, berdasarkan faktor pekerjaan suami, mereka juga menempati posisi teratas karena suami mereka bekerja di perusahaan elit. Kemudian berdasarkan faktor sekolah anak, Mama Ibuki dan Mama Mako menempati posisi tertinggi karena anak mereka berhasil masuk ke Taman Kanak-kanak yang elit, sedangkan Mama Megu menempati posisi menengah karena anaknya hanya dapat masuk ke TK yang biasa saja. Namun hal ini tidak mengubah posisi Mama Megu sebagai orang kelas atas karena ia menempati posisi tertinggi pada dua faktor sebelumnya.

\section{Kelas Menengah}

Adapun ibu yang termasuk ke dalam kelas menengah adalah Arisa dan Mama Miu. Hal ini dikarenakan pada faktor tempat tinggal, Arisa menempati posisi menengah karena tinggal di Bay East Tower yang harga sewanya tidak semahal Bay West Tower dan tidak semurah mansion Mama Miu. Sebaliknya, Mama Miu menempati posisi rendah karena mansion yang ditempatinya sudah nampak tua sehingga harga sewanya tidak semahal tower mansion.

Kemudian berdasarkan faktor pekerjaan suami, Arisa juga menempati posisi menengah karena suaminya bekerja di sebuah perusahaan IT yang bukan termasuk ke dalam perusahaan elit, sedangkan suami Mama Miu bekerja sebagai permbuat sushi di restoran sushi biasa sehingga Mama Miu menempati posisi rendah.

Selain itu, berdasarkan faktor sekolah anak, Arisa menempati kategori rendah karena anaknya dimasukkan ke sebuah hoikuen dan bukan youchien, sedangkan Mama Miu menyekolahkan anaknya ke TK yang sama dengan anak Mama Megu sehingga dapat dikatakan menempati posisi menengah dalam hal ini. Faktor sekolah anak tersebut menjadi poin utama bagi Mama Miu untuk dapat masuk dalam kategori kelas menengah, walaupun pada faktor tempat tinggal dan pekerjaan suami termasuk dalam kategori rendah.

\section{SIMPULAN}

Berdasarkan hasil penelitian pada novel Happiness ditemukan tiga norma yang berlaku dalam kelompok mama tomo. Norma tersebut berupa mengutamakan harmoni dalam kelompok, berusaha mewujudkan harapan sosial masyarakat Jepang akan sosok istri yang baik dan ibu yang bijak atau 
ryousaikenbo, dan paham akan penggunaan honne dan tatemae. Kemudian jika dilihat dari segi ukuran kelompok, kelompok mama tomo Ibuki termasuk dalam kategori kelompok kecil karena hanya beranggotakan lima orang anggota. Kelompok tersebut dipimpin oleh Mama Ibuki dan diasisteni oleh Mama Megu, sedangkan Mama Mako, Arisa, dan Mama Miu hanya merupakan anggota biasa.

Kelompok mama tomo dalam novel Happiness terbentuk karena anggotanya memiliki beberapa kesamaan di antaranya tinggal di daerah yang sama di Distrik Koto, Tokyo, sama-sama memiliki anak perempuan, memiliki pola pikir yang sama, serta memiliki tujuan yang sama untuk mengajarkan anak cara bersosialisasi dan untuk saling berbagi pengalaman sebagai ibu. Selain itu, keuntungan berupa pertukaran informasi mengenai perilaku anak dan sekolah serta media untuk meningkatkan rasa percaya diri yang diperoleh dari kelompok mama tomo juga menjadi faktor pembentuk kelompok tersebut.

Pada novel Happiness juga ditemukan dua kelas sosial dalam kelompok mama tomo, yaitu kelas atas dan kelas menengah. Kelas atas diisi oleh Mama Ibuki, Mama Megu, dan Mama Mako, sedangkan kelas menengah diisi oleh Arisa dan Mama Miu. Penggolongan kelas sosial ini ditentukan berdasarkan faktor tempat tinggal, pekerjaan suami, dan sekolah anak.

\section{REFERENSI}

Baron, Robert S. dan Norbert L. Kerr. 2003. Group Process, Group Decision, Group Action (Second Edition). Philadelphia: Open University Press.

Davies, Roger dan Ikeno, Osamu. 2002. The Japanese Mind: Understanding Contemporary Japanese Culture. Tokyo: Tuttle Publishing.
Horton, Paul B. dan Chester L. Hunt. 1984. Sosiologi: Jilid 2 Edisi Keenam. (Aminuddin Ram, Pentj). Jakarta: Erlangga.

Kirino, Natsuo. 2013. Happiness. Tokyo: Koubunsha.

Ratna, Nyoman Kutha. 2014. Teori, Metode, dan Teknik Penelitian Sastra. Yogyakarta: Pustaka Pelajar.

Ritzer, George dan Douglas J. Goodman. 2004. Teori Sosiologi Modern. (Alimandan, Pentj). Jakarta: Prenada Media.

Saitou, Keiko. 2018. “A Mendokusai!” to Omotta Toki ni Yomu Mama Tomo no Kyorikan. Tokyo: Seishun Shuppansha.

Shirakawa, Touko. 2013. Kakudzukeau Onna-tachi: Joshi Kaasuto no Jitai. Tokyo: Popura Shinsho.

Wada, Hideki. 2008. Shougakusei no Ko o Motsu Mama ga Shitteokubeki Koto. Tokyo: PHP Kenkyuusha.

Wea, Novita Restiati Ina, 2016, "Sukuuru Kaasuto yang Tercermin dalam Manga Pika Ichi Karya Maki Youko dan Mochida Aki”, E-Jurnal Humanis, Fakultas Sastra dan Budaya Unud, 15, 177-184.

Wedayanti, Ni Putu Luhur, 2018, "Omotenashi, Spirit Keramahan Masyarakat Jepang Menyambut Tokyo Olympic 2020", Prosiding Seminar Nasional Sastra dan Budaya, 3, 352356.

Wellek, Rene dan Austin Warren. 2016. Teori Kesusastraan Rene Wellek \& Austin Warren. (Melani Budianta, Pentj). Jakarta: Gramedia. 